\title{
Resistance performance of four principal apple cultivars to woolly apple aphid, Eriosoma lanigerum (Hemiptera: Pemphigidae), by simulated seasonal temperature in northern China
}

\author{
Xiu-Mei Tan ${ }^{1} \cdot$ Zhuo-Shi Yang $^{1} \cdot$ Hao Zhou $^{1} \cdot$ Qin-Min Yang ${ }^{2} \cdot$ Hong-Xu Zhou $^{1}$ (1)
}

Received: 30 April 2020 / Accepted: 20 December 2020 / Published online: 16 January 2021

(c) The Author(s) 2021

\begin{abstract}
Woolly apple aphid (WAA), Eriosoma lanigerum (Hausmann) (Hemiptera: Pemphigidae), is a worldwide quarantine pest of apples. Understanding the resistance mechanism of various cultivars to WAA is important for the selection for durable resistance. Few studies have examined the resistance of different apple cultivars to WAA in China; among common varieties produced in China, Red Fuji is highly sensitive to WAA. In this study, the resistance to WAA of Red Fuji and three other common cultivars-Starkrimson, Jonagold, and Ralls Genet-was assessed based on the developmental and reproductive biological characteristics of aphids, assessed under four fixed temperatures: $20,25,30$, and $35^{\circ} \mathrm{C}$. We found the optimal temperature for WAA growth and reproduction to be $20-25^{\circ} \mathrm{C}$, at which temperature, aphids on Red Fuji showed the highest rate of reproduction, the highest number of colonies, and the greatest area covered by aphid colonies among the four cultivars. These attributes of WAA were significantly higher at $20-25{ }^{\circ} \mathrm{C}$ than at $30^{\circ} \mathrm{C}$. On Red Fuji, the most favorable variety, WAA showed its highest net reproductive rate $(127.3 \pm 13.3)$, intrinsic growth rate $(0.30 \pm 0.01)$, highest growth rate of the colony area $(1.35 \pm 0.02)$, and the lowest average generation time $\left(16.1 \pm 0.8\right.$ day) at $25{ }^{\circ} \mathrm{C}$. The aphids inoculated onto the four tested cultivars all died within 1 week at $35^{\circ} \mathrm{C}$. Overall, Red Fuji was highly susceptible, while Starkrimson, Jonagold, and Ralls Genet were partially resistant.
\end{abstract}

Keywords Apple cultivars · Woolly apple aphid $\cdot$ Temperature $\cdot$ Biological characteristics $\cdot$ Cultivar resistance

\section{Introduction}

Woolly apple aphid (WAA), Eriosoma lanigerum (Hausmann) (Hemiptera: Pemphigidae), is an important cosmopolitan quarantine pest of apples. Aphids generally colonize on branches, roots, bark, and injury sites, where WAA can cause various effects, including fruit deformation, shoot growth retardance, tree vigor lowering, apple yield

Handling Editor: Joe Louis.

Hong-Xu Zhou

hxzhou@qau.edu.cn

1 China-Australia Cooperation Base of Crop Health and Invasive Species, China-Australia Joint Institute of Agricultural and Environmental Health, College of Plant Health and Medicine, Qingdao Agricultural University, Qingdao 266109, Shandong, China

2 General Station of Plant Protection of Shandong Province, Jinan, China reduction, and, in extreme cases, tree death (Beers et al. 2010). Native to North American, woolly apple aphid has been widely found on nursery materials (Baker 1915) and become an important economic pest in most apple-producing regions. In China, woolly apple aphid was first found in Weihai, Shandong Province in 1914 and Dalian, Liaoning Province in 1929 (Lung et al. 1960). Since then, it has spread to Henan, Hebei, Yunnan, Shanxi, Xinjiang, Tibet, and other provinces of China (Zhang and Luo 2002) from where it continues to spread.

Woolly apple aphid is usually controlled by pesticide applications, but aphids often rest in bark cracks, which reduce their contact with pesticides, in addition to the protection provided by the waxy secretion on their bodies (Smith 1999). Aphelinus mali (Hausmann) (Hymenoptera: Aphelinidae), the most common endoparasitoid of woolly apple aphid, can control WAA through high parasitism rate. Mass rearing of A. mali and its large-scale release in orchards to suppress WAA, however, is not currently feasible, and a great deal of basic research is still needed before 
such augmentative biological control can be made effective (Asante and Danthanarayana 1992; Zhou et al. 2010).

Breeding crops for higher plant resistance provides a sustainable alternative to slow down or prevent field attack by woolly apple aphid, and previous studies have focused on the resistance of apple cultivars to woolly apple aphid. Abu-romman and Ateyyat (2014) investigated the relative resistance to woolly apple aphid of 22 apple varieties, assessing resistance levels based on tree infestation rates and ranked cultivars into six relative resistance/susceptibility categories, of which Fuji 6 was highly susceptible. In New Zealand, the susceptibility of sixteen apple varieties to woolly apple aphid was determined, among which Raritan was resistant, while Royal Gala and Court Pendu Plat were susceptible (Sandanayaka et al. 2005).

China is the world's largest apple producer, both in terms of cultivated area and total production. In China, Red Fuji accounts for $70 \%$ of the production area and $90 \%$ of stored apples (Chen et al. 2017). The spread of woolly apple aphid in China in recent years has coincided with the large-scale expansion of cultivation of Red Fuji in the main apple-growing areas, this variety having been introduced from Japan in 1960s and gaining great popularity in the 1980s. The Starkrimson apple, introduced to Shandong province from the United States in 1982, has become another dominant variety grown in China. Previous studies have shown that Red Fuji is highly sensitive, while Starkrimson and Jonagold show partial resistance to WAA (Wang et al. 2009, 2011). Population outbreaks of woolly apple aphid in China have increased in recent years (Zhou et al. 2015), and greater infestations of WAA may be related to changes in the relative proportion of resistant vs. susceptible apple varieties grown in China, especially the increasing dominance of Red Fuji in past decades.

Few previous studies of resistance of apple cultivars to WAA have taken temperature into consideration. Wang et al. (2011) found that the intensity of population outbreaks of WAA in orchards fluctuated with temperature across the growing season (from April to late October). This study was conducted to explore the resistance mechanism of four apple cultivars (Red Fuji, Starkrimson, Jonagold and Ralls Genet) to woolly apple aphid based on the aphid's developmental and reproductive biology under different temperatures, for a better understanding of the seasonal dynamics of WAA on different cultivars. Our results will help in the selection of new resistant varieties and improvement of the Red Fuji cultivar through transgenic technology to achieve sustainable suppression of woolly apple aphid.

\section{Materials and methods}

\section{Sources of apple varieties and woolly apple aphids}

The flower buds of four apple varieties, such as Red Fuji, Starkrimson, Jonagold, and Ralls Genet, were grafted onto the rootstock Malus robusta Rehd, in an apple nursery at Qixia County, Shandong province in the summer of 2016. Routine management was conducted to provide water and organic fertilizer, and integrated pest management was used to control diseases and insect pests. In the following spring, each of the apple seedlings, then one meter high, was transplanted into a flower pot (Dia $20 * \mathrm{H} 25 \mathrm{~cm}$ ) and cultivated in a greenhouse.

Apterous woolly apple aphids were collected from a Qixia apple orchard in the spring of 2017, and used to inoculate the 2-year-old potted apple trees, which were held in a greenhouse, where the aphids gradually formed stable colonies.

\section{Biological characteristics of woolly apple aphid on different apple varieties at different temperatures}

Sixteen potted apple seedlings for each variety with similar size and vigor were collected and held at four fixed temperatures $\left(20,25,30\right.$, and $\left.35{ }^{\circ} \mathrm{C}\right), 60 \pm 10 \% \mathrm{RH}$, and a $14 \mathrm{~h}: 10 \mathrm{~h}$ L: D photoperiod in a greenhouse. Three wounds, each $2 \mathrm{~mm}$ wide and $20 \mathrm{~mm}$ long, were cut on the stem of each seedling as aphid colonization sites. Fifteen adult aphids were inoculated into each wound. The number of aphid colonies, and aphids in each colony, plus the wax area, were determined every $24 \mathrm{~h}$, and after 18 days all aphids were collected with a soft brush and counted.

\section{Life parameters of woolly apple aphid on different apple varieties at $25 \pm 1{ }^{\circ} \mathrm{C}$}

Using the same methods described above, potted trees of the same four apple varieties were produced and then held at $25^{\circ} \mathrm{C}, 60 \pm 10 \% \mathrm{RH}$, and a $14 \mathrm{~h}: 10 \mathrm{~h} \mathrm{~L}$ : D photoperiod. Three wounds were cut on the stem of each seedling, and 15 adult aphids (reared as described above) were inoculated into each wound. After new nymphs were born, only $101^{\text {st }}$ instar nymphs were retained on each seedling with all other adult aphids being removed. Thereafter, the molting of each nymph was observed and recorded every day, and its instar was recorded. When nymphs became adults, the new nymphs produced by these adults were removed daily, and the number was recorded until all adults died. 


\section{Data analysis}

The net reproductive rate $\left(R_{0}\right)$, average generation cycle $(T)$, innate rate of increase $(\gamma \mathrm{m})$, and finite rate of increase $(\lambda)$ were used to analyze the data of WAA life parameters when reared at $25 \pm 1{ }^{\circ} \mathrm{C}$. The net reproductive rate $\left(R_{0}\right)$ was calculated as below:

$R_{0}=\Sigma l_{\mathrm{x}} m_{\mathrm{x}}, T=\Sigma x l_{\mathrm{x}} m_{\mathrm{x}} / R_{0}, \gamma_{m}=\ln R_{0} / T, \lambda=e^{\gamma m}$

where $x$ is a specific age, and the time step used in our study was 1 day, $l_{\mathrm{x}}$ is the survival rate in a specific age, and $m_{\mathrm{x}}$ is the average number of progeny per female during the period of $x$ ( 1 day).

SPSS20 was used for analysis of variance with LSD multiple comparison. Excel 2013 was used to draw histogram and curve charts according to the experimental design.

\section{Results}

\section{Numbers of woolly apple aphids, number of aphid colonies, and total wax area on different varieties at 20,25 , and $30{ }^{\circ} \mathrm{C}$}

Two-way ANOVA was used to compare numbers of aphids and the number of colonies as well as the total area of woolly wax after 18 days of rearing (Table 1). Apple varieties had significant effects on numbers of aphids, number of colonies, and total wax area $(P<0.05)$, while the rearing temperature had significant effects on numbers of aphids and total wax area $(P<0.05)$. There was a significant interaction between apple varieties and temperature on number of aphids $(P=0.007<0.05)$ and total wax area $(P=0.032<0.05)$, but not numbers of colonies $(P=0.728>0.05)$.

The average number of aphid progeny produced on Red Fuji, averaged over all three temperatures of 20, 25, and $30{ }^{\circ} \mathrm{C}(332.0 \pm 29.0)$, was significantly higher than that for Starkrimson $(F=3.181, P=0.047)$, Jonagold $(F=3.181$, $P=0.030)$, and Ralls Genet $(F=3.181, P=0.033)$ (with no significant difference among the three varieties) (Fig. 1).

Meanwhile, apple varieties had different effects on the reproduction of woolly apple aphids at different temperatures (Fig. 2). At 18 days post-inoculation, Red Fuji showed a significantly higher level of aphid reproduction compared to the other three cultivars at $20{ }^{\circ} \mathrm{C}(F=6.032, P=0.013,0.002$, 0.004 for Starkrimson, Jonagold, and Ralls Genet, respectively) and $25^{\circ} \mathrm{C}(F=6.587, P=0.003,0.010,0.000$ for the above three varieties, respectively). At $30{ }^{\circ} \mathrm{C}$, the number of aphid progeny on Red Fuji (125.4) was significantly higher than that on Starkrimson $(56.67, F=3.138, P=0.022)$, but insignificantly on Ralls Genet $(123.33, F=3.181, P=0.947)$ and Jonagold (78.88, $F=3.181, P=0.118$ ).

Colonies on the four apple varieties had similar population dynamics, there being about 1-4 colonies on all four cultivars at three fixed temperatures in the first week after inoculation (Fig. 3). The number of aphid colonies on Red Fuji began to increase sharply from the 7-8th day, to levels higher than those on the other three cultivars, which continued until the 18th day when the experiment ended (due to declining plant vigor of the test seedlings). On the 18th day, Red Fuji had the highest number of aphid colonies at $20{ }^{\circ} \mathrm{C}(9.0 \pm 2.4), 25^{\circ} \mathrm{C}$ $(7.6 \pm 2.8)$, and $30{ }^{\circ} \mathrm{C}(5.2 \pm 1.7)$, significantly higher
Table 1 The effect variance of different apple varieties and temperatures $\left({ }^{\circ} \mathrm{C}\right)$ on offspring number, colony area, and colony number of woolly apple aphids $(\mathrm{Mean} \pm \mathrm{SE})$

\begin{tabular}{lrrrr}
\hline Source of variance & $\begin{array}{l}\text { Free degree } \\
(\mathrm{df})\end{array}$ & Mean square & $F$ value & $P$ value \\
\hline Offspring number & & & & \\
$\quad$ Corrected model & 11 & $83,782.989$ & 7.186 & $0.000^{*}$ \\
Incubation Temperature & 2 & $118,995.374$ & 10.206 & $0.000^{*}$ \\
Apple varieties & 3 & $161,320.750$ & 13.836 & $0.000^{*}$ \\
Incubation temperature $\times$ apple varieties & 6 & $38,842.111$ & 3.331 & $0.007^{*}$ \\
Colony area & 11 & $39,304.436$ & 6.080 & $0.000^{*}$ \\
Corrected model & 11 & $39,304.436$ & 6.080 & $0.000^{*}$ \\
Incubation temperature & 2 & $70,772.536$ & 10.948 & $0.000^{*}$ \\
Apple varieties & 3 & $65,723.051$ & 10.167 & $0.000^{*}$ \\
Incubation temperature $\times$ apple varieties & 6 & $16,171.257$ & 2.502 & $0.032^{*}$ \\
Colony number & & & & \\
Corrected model & 11 & 25.848 & 3.265 & $0.002^{*}$ \\
Incubation temperature & 2 & 24.420 & 3.085 & 0.053 \\
Apple varieties & 3 & 68.019 & 8.592 & $0.000^{*}$ \\
Incubation temperature $\times$ apple varieties & 6 & 4.766 & 0.602 & 0.728 \\
\hline
\end{tabular}

* Means significant differences 
Fig. 1 Average numbers of reproductive woolly apple aphids at 20,25 , and $30^{\circ} \mathrm{C}$
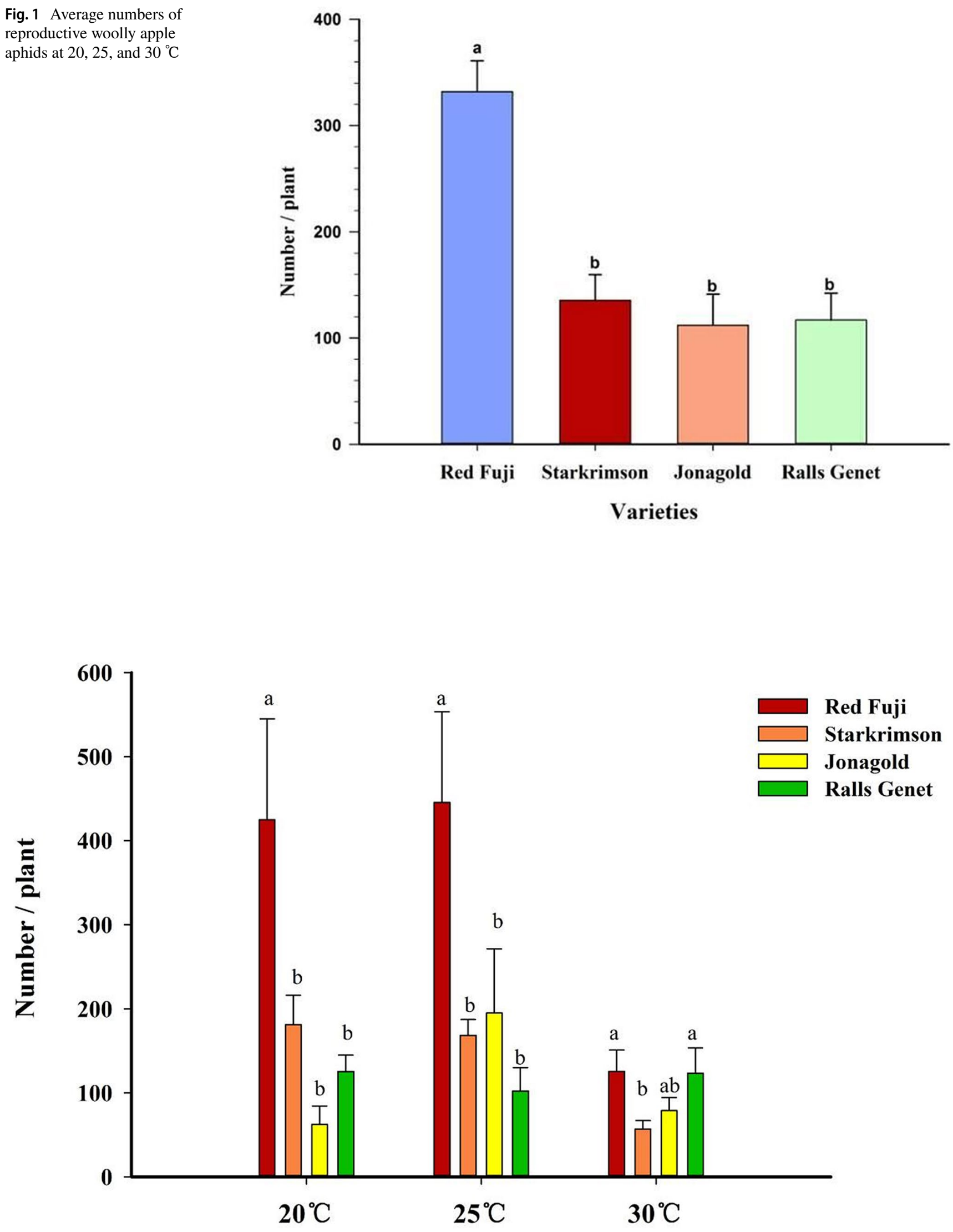

Fig. 2 Total numbers of woolly apple aphids at 18 days post-inoculation on different apple varieties at 20,25 , and $30{ }^{\circ} \mathrm{C}$ 
Fig. 3 Dynamics of colony numbers of woolly apple aphids on different apple varieties at 20,25 and $30^{\circ} \mathrm{C}$
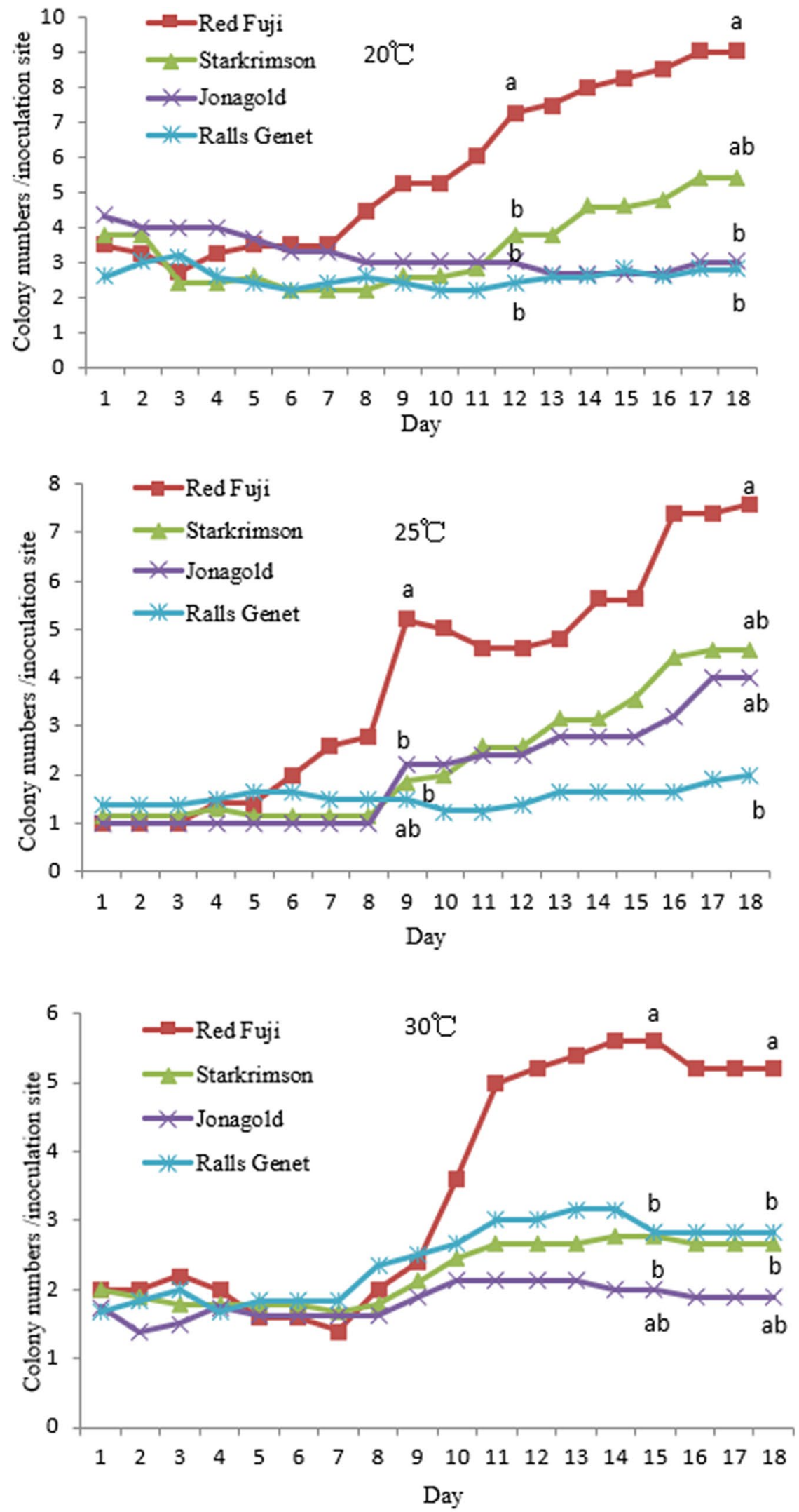
than Jonagold ( $3.0 \pm 0.6, F=4.556, P=0.013)$ and Ralls Genet $(2.8 \pm 0.4, F=4.556, P=0.005)$ at $20{ }^{\circ} \mathrm{C}$, Ralls Genet $(2.0 \pm 0.4, F=2.547, P=0.011)$ at $25{ }^{\circ} \mathrm{C}$, and Jonagold $(1.9 \pm 0.4, F=2.692, P=0.011)$ and Starkrimson $(2.7 \pm 0.6, F=2.692, P=0.037)$ at $30{ }^{\circ} \mathrm{C}$. The three cultivars other than Red Fuji fluctuated slightly in colony number after aphids settled on the inoculated sites.

Also, the four apple cultivars showed similar dynamic changes in total wax area of aphids at 20 and $25{ }^{\circ} \mathrm{C}$, with an increasing trend with time during the 18 days, while the increase of wax areas topped after the 14th day and fluctuated thereafter at $30{ }^{\circ} \mathrm{C}$ (Fig. 4). Red Fuji also showed the highest increase in wax area at all three temperatures as it did for colony number. From the 7 th day $\left(20{ }^{\circ} \mathrm{C}\right)$ and the 9th day $\left(25^{\circ} \mathrm{C}\right)$, the total wax area on Red Fuji began to increase sharply, significantly higher than that on the other three varieties, among which the wax area on Starkrimson exceeded that on Jonagold or Ralls Genet. The total wax area on the four varieties at $30{ }^{\circ} \mathrm{C}$ also increased gradually as time went on, with that on Red Fuji and Ralls Genet increasing faster than Starkrimson and Jonagold from the 8th day on. On the 18th day, wax areas on Red Fuji at $20{ }^{\circ} \mathrm{C}$ $\left(174.0 \pm 53.2 \mathrm{~cm}^{2}\right)$ and $25^{\circ} \mathrm{C}\left(346.2 \pm 73.9 \mathrm{~cm}^{2}\right)$ were significantly higher than those on Starkrimson $(87.0 \pm 13.3$ $\mathrm{cm}^{2}, F=4.624, P=0.040 ; 203.3 \pm 45.9 \mathrm{~cm}^{2}, F=7.667$, $P=0.030$, respectively, for the two temperatures), Jonagold $\left(19.0 \pm 9.9 \mathrm{~cm}^{2}, F=4.624, P=0.003 ; 124.0 \pm 27.7\right.$ $\mathrm{cm}^{2}, F=7.667, P=0.003$, respectively), and Ralls Genet $\left(74.2 \pm 13.5 \mathrm{~cm}^{2}, F=4.624, P=0.021 ; 92.4 \pm 27.8 \mathrm{~cm}^{2}\right.$, $F=7.667, P=0.000$, respectively), with no significant difference among the three. At $30{ }^{\circ} \mathrm{C}$, the total wax area on Red Fuji $\left(155.0 \pm 44.5 \mathrm{~cm}^{2}\right)$ was also significantly higher than on Starkrimson $\left(58.7 \pm 8.0 \mathrm{~cm}^{2}, F=2.692, P=0.037\right)$ and Jonagold $\left(64.9 \pm 12.7 \mathrm{~cm}^{2}, F=2.692, P=0.011\right)$, but not than on Ralls Genet $\left(74.2 \pm 13.5 \mathrm{~cm}^{2}, F=2.692, P=0.057\right)$.

\section{Comparison of colonization level and survival time of woolly apple aphid on different varieties at $35^{\circ} \mathrm{C}$}

After 15 aphids were inoculated on each experiment site of four apple cultivars at $35{ }^{\circ} \mathrm{C}$ (Fig. 5), the total number of WAA including adults and reproductive nymphs on Ralls Genet was higher than those on the other three cultivars, significantly higher in the first 5 days $(\mathrm{df}=3 ; F=3.158$, 9.959, 11.386, 9.031, and 4.059, respectively; $P=0.047$, $0.000,0.000,0.001$, and 0.021 , respectively, all $<0.05$ ). All inoculated aphids and reproductive nymphs, however, died within 11 days, with the average survival time (time until death of all aphids) on Ralls Genet ( $6.3 \pm 0.8$ day) and Starkrimson $(5.7 \pm 1.4$ day) being longer than that on Jonagold ( $3.8 \pm 1.7$ day) and Red Fuji ( $4.5 \pm 1.1$ day), though not significantly so.
Comparison of nymphal duration, adult longevity, and progeny numbers of woolly apple aphid at $25^{\circ} \mathrm{C}$

The developmental duration for first-instar nymphs to become adults on Red Fuji ( $8.6 \pm 0.5$ day) and adult longevity $(18.8 \pm 1.0$ day) was the shortest among the four cultivars, with progeny number $(142.9 \pm 8.8)$ being secondary only to Jonagold $(156.2 \pm 3.2)$ (Table 2). Meanwhile, aphid nymphs on Starkrimson had the longest developmental period, but adult aphids on that variety also had the highest longevity $(25.0 \pm 1.3$ day $)$, significantly greater than that on Red Fuji (18.8 \pm 1.0 day, $F=3.173, P=0.007)$ and Ralls Genet $(20.3 \pm 1.5$ day, $F=3.173, P=0.020)$. The number of progeny aphids on Ralls Genet (116.8 \pm 9.3$)$ was the lowest of the four varieties tested, significantly lower than on Jonagold $(F=3.364, P=0.014)$.

\section{Net reproductive rate, average generation time, intrinsic rate of increase, and finite rate of increase of woolly apple aphid at $25{ }^{\circ} \mathrm{C}$}

WAA on Red Fuji showed the highest net reproductive rate $(127.3 \pm 13.3)$, intrinsic growth rate $(0.30 \pm 0.01)$, colony area growth rate $(1.35 \pm 0.02)$, and the lowest average generation time ( $16.1 \pm 0.8$ day), among which both the intrinsic rate $(F=4.739, P=0.035)$ and colony area growth rate values $(F=4.851, P=0.033)$ were significantly higher than those of aphids on the other three varieties (Table 3). Meanwhile, WAA on Jonagold had the lowest intrinsic growth rate and colony area growth rate, and the longest generation time, only with the net reproductive rate insignificantly higher than on Rall Genet $(F=2.998, P=0.154)$. The net reproductive rate on Rall Genet $(73.7 \pm 10.1)$ was the lowest of the four varieties, significantly lower than that on Fuji $(127.3 \pm 13.3, F=2.998, P=0.024)$ and Starkrimson $(118.8 \pm 11.4, F=2.998, P=0.047)$.

\section{Discussion}

Previous investigations on woolly apple aphid in China showed the presence of two annual peaks, the first and highest peak from late May to late July, and the second one from early September to late October (Wang et al. 2011). In Shandong province, woolly apple aphid populations usually begin to increase sharply, with aphids to produce their characteristic white wax, from mid-to-late April, when the average daily high temperature is above $20{ }^{\circ} \mathrm{C}$. In order to fully simulate the temperature ranges that occur during the field growing season in Shandong apple orchards, we carried out our varietal laboratory trial at four temperatures: 20, 25, 30 , and $35^{\circ} \mathrm{C}$, and our results demonstrated that temperature had an important influence on the biological characteristics 
Fig. 4 Dynamics of colony areas of woolly apple aphids on different apple varieties at 20 , 25 , and $30^{\circ} \mathrm{C}$
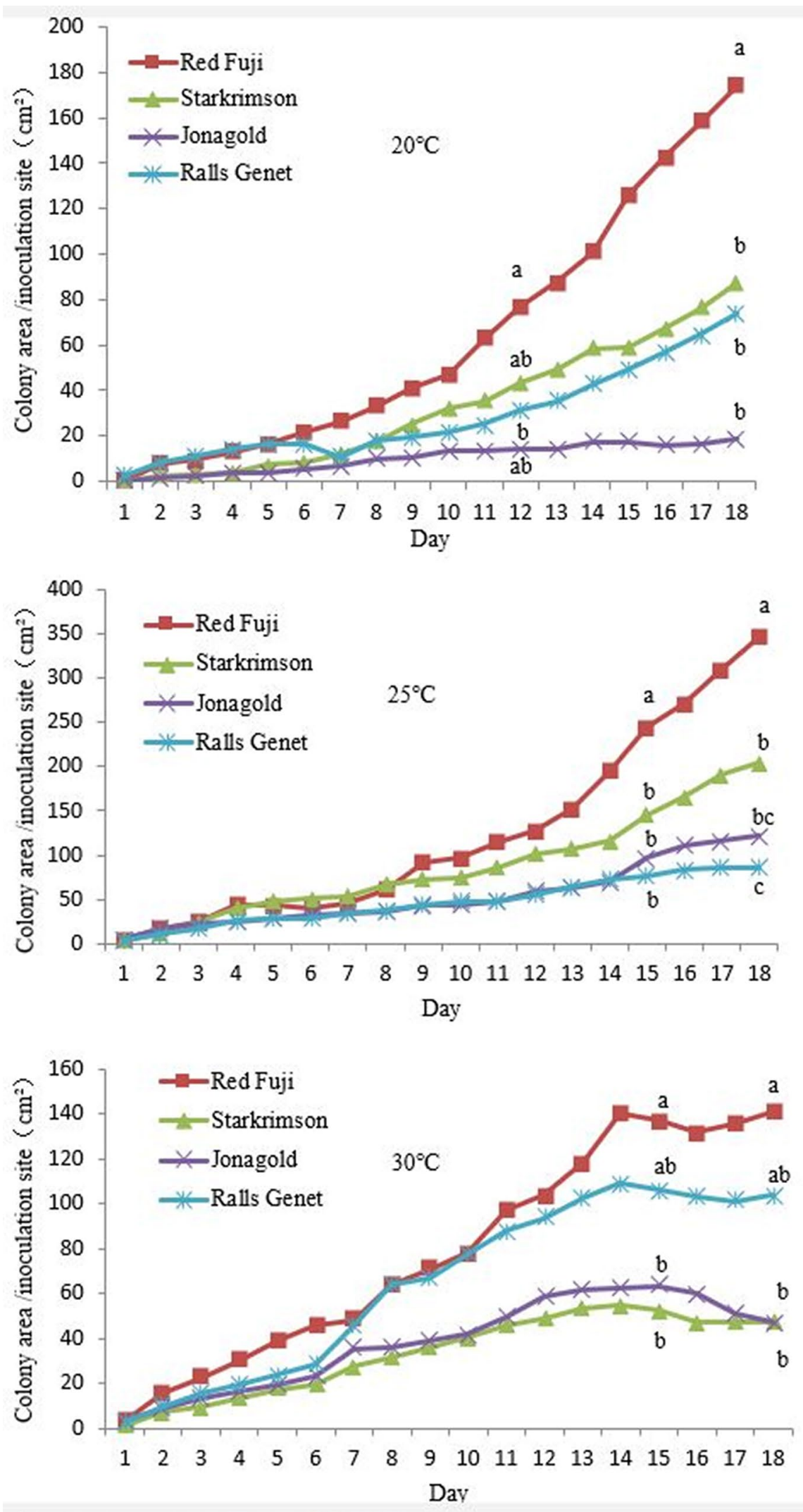
Fig. 5 Total number and survival time of woolly apple aphids on different apple varieties at $35^{\circ} \mathrm{C}$

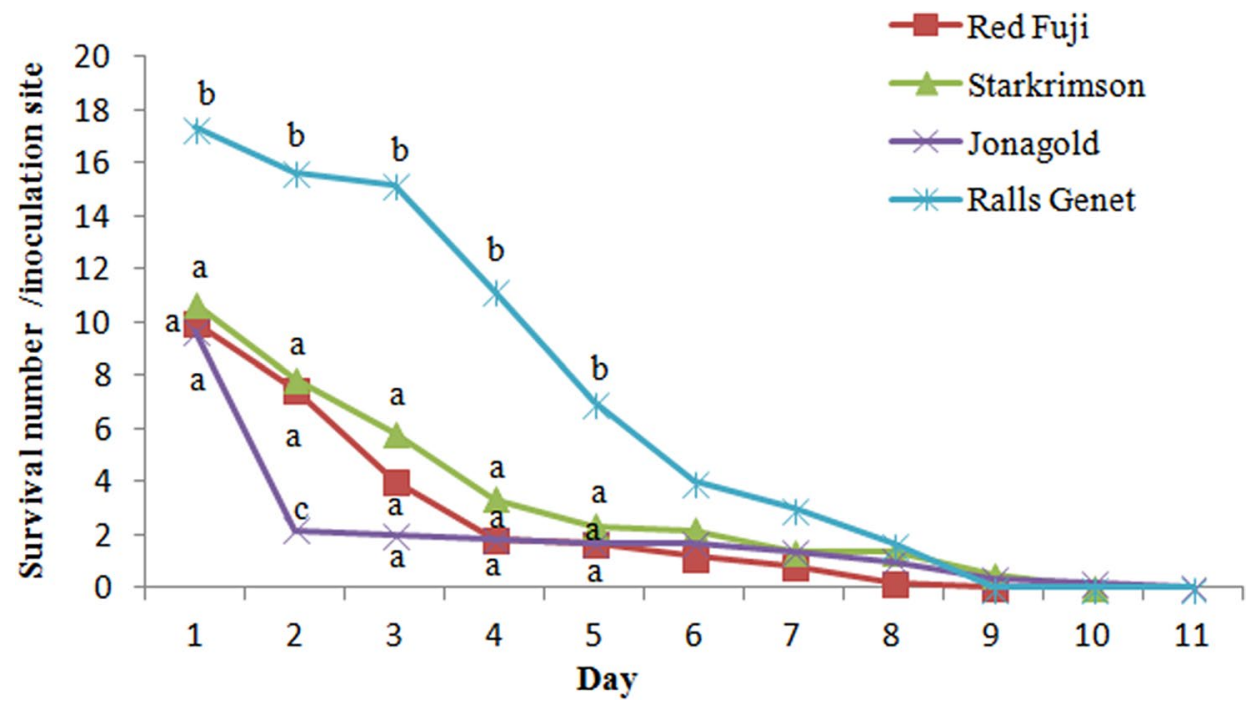

Table 2 The nymphal developmental duration, adult longevity, and progeny number of woolly apple aphids on four apple varieties at $25{ }^{\circ} \mathrm{C}($ mean $\pm \mathrm{SE})$

\begin{tabular}{lcll}
\hline Apple varieties & $\begin{array}{l}\text { Nymph devel- } \\
\text { opment dura- } \\
\text { tion (day) }\end{array}$ & $\begin{array}{l}\text { Adults' longev- } \\
\text { ity } \\
\text { (day) }\end{array}$ & Progeny number \\
\hline Red Fuji & $8.6 \pm 0.5 \mathrm{a}$ & $18.8 \pm 1.0 \mathrm{a}$ & $142.9 \pm 8.8 \mathrm{ab}$ \\
Starkrimson & $10.4 \pm 0.6 \mathrm{~b}$ & $25.0 \pm 1.3 \mathrm{~b}$ & $137.0 \pm 12.0 \mathrm{ab}$ \\
Jonagold & $9.4 \pm 0.4 \mathrm{ab}$ & $22.6 \pm 1.3 \mathrm{ab}$ & $156.2 \pm 3.2 \mathrm{a}$ \\
Ralls Genet & $9.8 \pm 0.4 \mathrm{ab}$ & $20.3 \pm 1.5 \mathrm{a}$ & $116.8 \pm 9.3 \mathrm{~b}$ \\
\hline
\end{tabular}

The same letter in the same column indicates no significant difference, while different letters indicate significant difference

of woolly apple aphid populations. The number of aphids, the number of colonies, and colony size were all greatest at $20-25^{\circ} \mathrm{C}$, and gradually decreased with higher temperatures, similar to the findings of Yu et al. (1989), who determined that the optimum temperature for reproduction for WAA was about $25^{\circ} \mathrm{C}$. Higher temperatures were unfavorable: at $35^{\circ} \mathrm{C}$, when 15 aphids were inoculated onto each of four varieties all died within 1 week, with only slight differences in their survival time. This adverse impact of high temperatures on WAA explains why peak populations do not occur during the hottest summer days in July or August when the temperature highs are $30-35^{\circ} \mathrm{C}$. Brown and Schmitt (1994) also found a gradual decline in WAA abundance on trees in the summer after June, followed by a slight increase in September.

Based on the population dynamics of WAA in apple orchards and laboratory experiment, we hypothesized that $20-25{ }^{\circ} \mathrm{C}$ would be optimal for growth and development of woolly apple aphid, a range that corresponds with the first population peak in orchards in early summer. The following hotter summer months are not conducive to the growth and development of apple aphid, as shown by the rapid death of WAAs at $35^{\circ} \mathrm{C}$ in our experiment. When temperatures drop in the fall and return to about $20{ }^{\circ} \mathrm{C}$, aphids experience another population peak.

Many plants produce secondary substances to enhance their pest resistance (Francia et al. 2007; Zhou et al. 2013). Analysis of volatiles extracted from apple branches, when presented to aphids in a Y-tube olfactometer, showed lowest resistance of branches from Fuji and Shasan varieties (Wang et al. 2009). Yin et al. (2010) have shown that resistance to woolly apple aphid is related to the strength of capillary tension in apple xylem and that this tension is low in Red Fuji and Gold Marshal and higher in more resistant varieties. In another study, changes in the physiological index (including
Table 3 The life table index of woolly apple aphids on four apple varieties at $25^{\circ} \mathrm{C}$ $($ mean $\pm \mathrm{SE})$

\begin{tabular}{lclll}
\hline Apple varieties & Net reproductive rate & $\begin{array}{l}\text { Average genera- } \\
\text { tion time (days) }\end{array}$ & Intrinsic growth rate & Colony area growth rate \\
\hline Red Fuji & $127.3 \pm 13.3 \mathrm{a}$ & $16.1 \pm 0.8 \mathrm{a}$ & $0.30 \pm 0.01 \mathrm{a}$ & $1.35 \pm 0.02 \mathrm{a}$ \\
Starkrimson & $118.8 \pm 11.4 \mathrm{a}$ & $19.1 \pm 0.7 \mathrm{ab}$ & $0.25 \pm 0.01 \mathrm{~b}$ & $1.28 \pm 0.02 \mathrm{~b}$ \\
Jonagold & $103.0 \pm 18.5 \mathrm{ab}$ & $19.9 \pm 0.6 \mathrm{~b}$ & $0.23 \pm 0.01 \mathrm{~b}$ & $1.26 \pm 0.02 \mathrm{~b}$ \\
Ralls Genet & $73.7 \pm 10.1 \mathrm{~b}$ & $18.2 \pm 1.5 \mathrm{ab}$ & $0.24 \pm 0.02 \mathrm{~b}$ & $1.27 \pm 0.02 \mathrm{~b}$ \\
\hline
\end{tabular}

The same letter in the same column indicates no significant difference, while different letters indicate significant difference 
soluble sugar, protein, free amino acids, total phenolic compounds and defense enzymatic activities) of six cultivars before and after the damage by woolly apple aphid were correlated to the degree of aphid resistance of the tested host cultivars (Wang et al. 2012). Host plant resistance offers an alternative means for integrated pest management (IPM) to control pests in orchards (Nwosu and Adedire 2019). Previous studies on the development of new resistant apples lines and molecular studies of the genetics of resistance in WAA showed that host plant resistance varied among apple cultivars to woolly apple aphid in worldwide (Ateyyat and Al-Antary 2009; Abu-Romman and Ateyyat 2014; Sandanayaka et al. 2003; Nicholas et al. 2005).

The four cultivars tested in this study are primarily grown in northern Chinese apple-growing areas, including two mid-season cultivars (Starkrimson and Jonagold), and two late maturity ones (Red Fuji and Ralls Genet), among which Red Fuji has been the dominant cultivar nationwide in recent decades. Since the Fuji cultivar originated from the hybridization of Ralls Genet as the female parent and Red Delicious (of which Starkrimson is one of the Delicious series) as the male parent, the study on their resistance difference to WAA is helpful to elucidate the resistance mechanism of cultivars, which should provide some useful information for future breed improvement.

By direct inoculation of aphids on apple seedlings, it was found that the resistance of tested varieties differed with temperature, reflecting, to some extent, the seasonal pattern of resistance of difference apple cultivars in orchards. The number of apple aphids, aphid colonies, and the colony area on Red Fuji were all the highest at 20 and $30{ }^{\circ} \mathrm{C}$, indicating its high susceptibility to WAA.

When the host is Ralls Genet, the increase in total number of aphids and in colony area was second only to Red Fuji from the 8th day after inoculation at $30{ }^{\circ} \mathrm{C}$, with colony area being significantly higher on Ralls Genet than on Starkrimson or Jonagold. Also, the survival time of aphids at $35^{\circ} \mathrm{C}$ on Ralls Genet was the longest. This greater survival may be related to the physiological characteristics of the Ralls Genet variety at relatively high temperatures, a thought supported by the fact that for the 1-year seedlings used in our experiment, Ralls Genet seedlings grew better than the other three varieties if temperatures were above $30^{\circ} \mathrm{C}$. The relative success of the growth of Ralls Genet may shield aphids from the effects of high temperatures and provide more nutrients, making this variety more conducive to the growth and reproduction of WAA. Though relatively resistant to aphids, Jonagold, Ralls Genet and Starkrimson showed no consistency in their relative levels of resistance when evaluated at different temperatures. Field investigation of WAA's preferences among cultivars in orchards also indicated minor differences in tested years (Wang et al. 2011), and it is speculated that the resistance of different apple varieties may be affected by year, season, temperature, light, and rainfall.

A suitable condition $\left(25 \pm 2{ }^{\circ} \mathrm{C}, \mathrm{RH} 60 \pm 10 \%\right)$ was selected to determine the life parameters of apple aphid on four apple varieties, taking intrinsic growth rate and circumferential growth rate of colony area as the index of resistance evaluation. The index of population growth, the total wax area, adult longevity, and nymphal developmental time were also evaluated. Red Fuji showed the shortest developmental time for nymphs and the shortest longevity for adults, but with relative high progeny number, indicating WAA's faster growth and greater reproductive generations on Red Fuji; with the highest net reproductive rate, intrinsic growth rate, and rate of increase of colony area circumference, it is safe to say that Red Fuji was highly susceptible compared with other cultivars. Jonagold, which showed the lowest intrinsic and growth rate of the periphery of colonies, and the longest generation time, had the highest level of resistance to WAA of the four cultivars tested. Taking all life table index into consideration, we rated that the relative level of resistance of the four tested varieties to woolly apple aphid as Jonagold $>$ Ralls Genet $>$ Starkrimson $>$ Red Fuji. Our study was conducted by inoculation of aphids on seedlings, but our findings that Red Fuji showed the highest susceptibility to WAA agreed with the orchard-level investigation by Wang et al. (2011) who found Jonagold and Starkrimson to be relatively resistant to aphids compared with Red Fuji. Thus, the high susceptibility of Red Fuji has been noted previously (Wang et al. 2009, 2011; Yin et al. 2010), as well as the partial resistance of the other three varieties we tested.

Red Fuji is the dominant cultivar in the four main applegrowing regions of China, which may explain why aphids on apples have increased in importance in recent years. Therefore, the breeding for better resistance of the dominant varieties and the expansion of resistant varieties will help reduce damage from WAA. The differences among cultivars regarding their levels of WAA infestation can potentially be applied in apple breeding to achieve more effective and environmentally friendly pest control.

Resistance mechanisms of plants to insects are complex and influenced by the external environment, a plant's growing conditions, and the nutritional components and secondary metabolites of different varieties. Susceptibility of apple cultivars to WAA infestation is a kind of trait, and in general, such traits can be divided into qualitative versus quantitative traits. Plant resistance traits (to insects) are mostly quantitative characters, easily affected by the environment and controlled by minor effects of polygenes (Liu et al. 2011). It is speculated that the resistance of apple varieties to WAA is controlled by multiple genes. Identification and mapping of new resistance genes are an ongoing process in apple breeding (Bus et al. 2008, 2010; Abu-Romman and Ateyyat 2014). Previous studies have shown that some quantitative trait loci 
related to the resistance of WAA have been preliminarily identified (Ruiz-Montoya et al. 2015), and three major resistant genes to WAA have been identified in different apple varieties, including Er1 on Northern Spy (Malus domestica) (Knight et al. 1962), Er2 on Robusta 5 (Malus $\times$ robusta) (King et al. 1991), and Er3 on Aotea (Malus sieboldii) in 2003 (Sandanayaka and Hale 2003). Also, studies on some molecular markers and linkage localization were carried out on the single resistance genes in these varieties, but the complete sequences of these resistance genes have not been obtained so far (Bus et al. 2008, 2010; Fischer et al. 2003; Abu-Romman and Ateyyat 2014). Thus, the accurate detection of resistance genes for WAA has been progressing slowly, and the mechanism of insect resistance needs further exploration to improve the control of woolly apple aphid (Dietrich and Dai 2016).

We confirmed that Red Fuji is highly susceptible to WAA, but that the other three varieties we tested showed some resistance. To date, resistance genes in these four major apple varieties have not been screened in China. Choosing Red Fuji, Ralls Genet, and Starkrimson, three closely related varieties, our research team has also been working on their transcriptome and proteome differences before and after being damaged by WAA, in order to find potential aphid resistance genes in resistant varieties and apply the information to molecular-assisted breeding to improve the Red Fuji variety through transgenic technology for durable aphid resistance. The findings in this study provide a theoretical basis for the study of the resistance mechanism of different apple varieties to WAA, and further studies are required to mine the germplasm resources and resistance breeding in China.

Acknowledgements We are grateful to Wang Wenjiao and Chen Qizhao from the College of Plant Health and Medicine, Qingdao Agricultural University, China, for their help in the experiment. We further thank Roy Van Driesche for suggestions and advice on the manuscript. This work was funded by the National Natural Science Foundation (31772232), the Major Scientific and Technological Innovation Project of Shandong Province (2017CXGC0214), the National Key Research and Development Plan (2016YFC1201200), and the Taishan Mountain Scholar Constructive Engineering Foundation of Shandong, China.

\section{Compliance with ethical standards}

Conflict of interest All authors declare that they have no conflicts of interest.

Ethical approval This article does not contain any studies with human or animal performed by any of the authors.

Open Access This article is licensed under a Creative Commons Attribution 4.0 International License, which permits use, sharing, adaptation, distribution and reproduction in any medium or format, as long as you give appropriate credit to the original author(s) and the source, provide a link to the Creative Commons licence, and indicate if changes were made. The images or other third party material in this article are included in the article's Creative Commons licence, unless indicated otherwise in a credit line to the material. If material is not included in the article's Creative Commons licence and your intended use is not permitted by statutory regulation or exceeds the permitted use, you will need to obtain permission directly from the copyright holder. To view a copy of this licence, visit http://creativecommons.org/licenses/by/4.0/.

\section{References}

Abu-Romman S, Ateyyat M (2014) Phenotypic and aolecular screening of apple genotypes to woolly apple aphid resistance. Not Bot Hortic Agrobot Cluj-Napoca 42(1):99-103

Asante SK, Danthanarayana W (1992) Development of Aphelinus mali an endoparasitoid of woolly apple aphid, Eriosoma lanigerum at different temperatures. Entomol Exp Appl 65(1):31-37

Ateyyat MA, Al-Antary TM (2009) Susceptibility of nine apple cultivars to woolly apple aphid, Eriosoma lanigerum (Homoptera: Aphididae) in Jordan. Int J Pest Manage 1:79-84

Baker AC (1915) The woolly apple aphid. Report no. 101. U.S. Department of Agriculture, Washington, DC

Beers EH, Cockfield SD, Gontijo LM (2010) Seasonal phenology of woolly apple aphid (Hemiptera: Aphidoidea) in central Washington. Environ Entomol 39:286-294

Brown MW, Schmitt JJ (1994) Population dynamics of woolly apple aphid in West Virginia apple orchards. Environ Entomol 5:1182-1188

Bus VGM, Chagné D, Bassett HCM, Bowatte D, Calenge F, Celton J-M, Durel CE, Malone MT, Patocchi A, Ranatunga AC, Rikkerink EHA, Tustin DS, Zhou J, Gardiner SE (2008) Genome mapping of three major resistance genes to woolly apple aphid (Eriosoma lanigerum Hausm.). Tree Genet Genom 4:223-236

Bus VGM, Bassett HCM, Bowatte D, Chagné D, Ranatunga CA, Ulluwishewa D, Wiedow C, Gardiner SE (2010) Genome mapping of an apple scab, a powdery mildew and a woolly apple aphid resistance gene from open-pollinated Mildew Immune Selection. Tree Genet Genom 6(3):477-487

Chen X, Mao Z, Xiang S, Jiang Y, Wang Z, Zhang Z, Wang N, Xu H, Wang Y (2017) The breeding of new variety of easy colouring functional apple and non-bag cultivation technology. China Fruits 1:1-4

Dietrich GF, Dai W (2016) Mouthpart structure in the woolly apple aphid Eriosoma lanigerum (Hausmann) (Hemiptera: Aphidoidea: Pemphigidae). Arthropod Struct Dev 45:230-241

Fischer C, Fischer M, Geibel M, Luby J, Brewer L, Alspach P, Hofstee M, Bradley S, Bus V (2003) Increasing genetic diversity in apple breeding to improve the durability of pest and disease resistance. Acta Hortic 538:185-190

Francia D, Demaria D, Calderini O, Ferraris L, Valentino D, Arcioni S, Tamietti G, Cardinale F (2007) Wounding induces resistance to pathogens with different lifestyles in tomato: role of ethylene in cross-protection. Plant Cell Environ 30:1357-1365

King GL, Alston FH, Battle I (1991) The European apple genome mapping project-developing a strategy for mapping genes coding for agronomic characters in tree species. Euphytica 56(1):89-94

Knight RL, Briggs JB, Massee AM, Tydeman HM (1962) The inheritance of resistance to woolly aphid Eriosoma lanigerum (Hausmm.) in the apple. HortScience 37:207-218

Liu RX, Chen L, Jia ZH, Lu BB, Shi HL, Shao WL, Dong HS (2011) Transcription factor AtMYB44 regulates induced expression of the ETHYLENE INSENSITIVE2 gene in Arabidopsis responding to a harpin protein. Mol Plant Microbe Interact 24(3):377-389 
Lung CD, Wang YP, Tang PQ (1960) Investigations on the biology and utilization of Aphelinus mali Hald., the specific parasite of the woolly apple aphis, Eriosoma Lanigerum Hausm. Acta Entomol Sin 2:1-39

Nicholas AH, Spooner-Hart RN, Vickers RA (2005) Abundance and natural control of the woolly aphid Eriosoma lanigerum in an Australian apple orchard IPM program. Bio-Control 50:271-291

Nwosu LC, Adedire CO (2019) Effects of host resistance and plantderived insecticides on mortality of Sitophlius zeamais (Coleoptera: Curculionidae) adults in stored maize. Int J Trop Insect Sci 39(2):165-173

Ruiz-Montoya L, Ziga G, Cisneros R, Salinas-Moreno Y, Pea-Martnez R, Machkour-M'Rabet S (2015) Phenotypic and genetic variations in obligate parthenogenetic populations of Eriosoma lanigerum Hausmann (Hemiptera: Aphididae). Neotrop Entomol 44:534-545

Sandanayaka WRM, Hale CN (2003) Electronically monitored stylet penetration pathway of woolly apple aphid, Eriosoma lanigerum (Homoptera: Aphididae), on apple (Malus domestica). N Z J Crop Hortic Sci 31(2):107-113

Sandanayaka WRM, Bus VGM, Connolly P, Newcomb R (2003) Characteristics associated with woolly apple aphid Eriosoma lanigerum (Hausm.), resistance of three apple rootstocks. Entomol Exp Appl 109:63-72

Sandanayaka WRM, Bus VGM, Connolly P (2005) Mechanisms of woolly aphid Eriosoma lanigerum (Hausm.) resistance in apple. J Appl Entomol 129(9-10):534-541

Smith RG (1999) Wax glands, wax production and the functional significance of wax use in three aphid species (Homoptera: Aphididae). Ann Mag Nat Hist 33(4):513-530

Wang PY, Qi LM, Xun XG, Sun LG, Qu RZ (2009) Selectivity of branches from the Various Apple Varieties by Eriosoma lanigerum with Volatiles from the Branches. J Sci Silv Sin 45(8):91-95
Wang XC, Zhou HX, Guo JY, Wan FH, Yu Y (2011) Comparison of population dynamics of Eriosoma lanigerum Hausmann in different orchards. J Biosaf 20:220-226

Wang XC, Yu Y, Zhou HX, Cheng Z, Zhang AS, Men XY, Li LL (2012) Effects of Eriosoma lanigerum (Hausmann) on physiological indices of different apple cultivars. J Acta Ecol Sin 32(7):2075-2081

Yin XW, Li XY, Zhang L, Chen B (2010) Resistance determination of the apple varieties against the woolly apple aphid, Eriosoma lanigerum. J Yunnan Agric Univ 25(1):29-33

Yu B, Kuang RP, Shan F, Tang YZ, Zhong N (1989) Effect of temperature on the development of woolly apple aphid, Eriosoma lanigerum. Zool Res 02:51-55

Zhang QG, Luo WC (2002) Occurrence characteristics of Eriosoma lanigerum and its control methods. Chin Bull Entomol 39(5):340-342

Zhou HX, Guo JY, Wan FH, Yu Y (2010) Natural control of Aphelinus mali on Eriosoma lanigerum and the parasitoid's overwintering protection measures. Acta Phytophylacica Sin 37(02):153-158

Zhou HX, Wang XC, Yu Y, Tan XM, Cheng ZQ, Zhang AS, Men XY, Li LL (2013) Chemical characteristics of normal, woolly apple aphid-damaged, and mechanically damaged twigs of six apple cultivars, measured in autumn wood. J Econ Entomol 106(2):1011-1017

Zhou HX, Zhang RM, Tan XM, Tao YL, Wan FH, Wu Q, Chu D (2015) Invasion genetics of woolly apple aphid (Hemiptera: Aphididae) in China. J Econ Entomol 108(3):1040-1046

Publisher's Note Springer Nature remains neutral with regard to jurisdictional claims in published maps and institutional affiliations. 